\title{
Gender, Educational Attainment, and the Impact of Parental Migration on Children Left Behind *
}

\author{
Francisca M. Antman ${ }^{\dagger}$ \\ Department of Economics, University of Colorado at Boulder
}

May 16, 2012

\begin{abstract}
Estimation of the causal effect of parental migration on children's educational attainment is complicated by the fact that migrants and non-migrants are likely to differ in unobservable ways that also affect children's educational outcomes. This paper suggests a novel way of addressing this selection problem by looking within the family to exploit variation in siblings' ages at the time of parental migration. The basic assumption underlying the analysis is that parental migration will have no effect on the educational outcomes of children who are at least 20 because they have already completed their educations. Their younger siblings, in contrast, may still be in school, and thus will be affected by the parental migration experience. The results point to a statistically significant positive effect of paternal U.S. migration on education for girls, suggesting that pushing a father's U.S. migration earlier in his daughter's life can lead to an increase in her educational attainment of up to 1 year relative to delaying migration until after she has turned 20. In contrast, paternal domestic migration has no statistically significant effect on educational attainment for girls or boys, suggesting that father absence does not play a major role in determining children's educational outcomes. Instead, these results suggest that the marginal dollars from U.S. migrant remittances appear to enable families to further educate their daughters. Thus, policymakers should view international migration as a potential pathway by which families raise educational attainments of girls in particular.
\end{abstract}

JEL: O15; J12; J13; J16; J24; F22

Keywords: migration, father absence, education, gender

${ }^{*}$ I would like to thank Doug Bernheim, Luigi Pistaferri, Aprajit Mahajan, Terra McKinnish, Julie Berry Cullen, Silvia Giorguli Saucedo, Marie Mora, three anonymous referees, and the editor, Klaus F. Zimmermann, for helpful comments. Additionally, participants at the 2008 PAA meeting, seminar participants at Colorado State University, and participants of the public economics group, as well as the labor and development reading groups at Stanford University provided useful feedback. An earlier version of this paper was entitled "Parental Migration and Child Education: Evidence from Variation in Child Age During Parental Absence." My thanks go to an anonymous referee for inspiring a reframing of this paper. Any errors are my own. This research was supported by the Leonard W. Ely and Shirley R. Ely Graduate Student Fund through a grant to the Stanford Institute for Economic Policy Research.

${ }^{\dagger}$ Contact: francisca.antman@colorado.edu, Department of Economics, University of Colorado at Boulder, 256 UCB, Boulder, CO 80309. Telephone 1(303)492-8872. Fax 1(303)492-8960. 


\section{Introduction}

While the public debate over immigration in the United States still mostly focuses on families wishing to settle permanently in that country, studies show that about half of undocumented Mexican migrants to the U.S. return to Mexico within two years (Reyes, 1997). In addition, data on Mexican migrants to the U.S. reveal that a substantial majority of male heads of household with families in Mexico leave at least one minor child at home. ${ }^{1}$ These facts have brought newfound attention to the consequences of these separations for the educational outcomes of the children of Mexican migrants-children who will one day become labor market participants in Mexico, and potentially the U.S. as well. This paper examines this important question by exploiting the variation in siblings' ages at the time of parental migration. I focus here on paternal migration because, as will be shown, Mexican fathers are much more likely to migrate.

Theoretically, it is unclear whether paternal migration should have a net positive or negative effect on children's education. ${ }^{2}$ On the one hand, the father is likely to be earning more in the U.S. than at home in Mexico, and the remittances from these earnings are likely to enable the child to devote more time to schoolwork and attain a higher level of education. ${ }^{3}$ However, the father's absence may impose a psychological cost on the child and may require the child to devote more time to the family or labor force to compensate for parental absence.

\footnotetext{
${ }^{1}$ Author's own calculation from the Mexican Migration Project 118 (MMP118). http://mmp.opr.princeton.edu/

${ }^{2}$ See Antman (forthcoming) for a review of the literature on the impact of parental migration on children left behind.

${ }^{3}$ Consistent with this notion, Yang (2008) finds that Philippine households experiencing favorable exchange rate shocks tied to the migration of family members increase educational investments in their children.
} 
In addition, the father's migration may teach the child about the viability of international migration as a possible career path-one in which the child's Mexican education may not be highly valued. Finally, paternal migration may change the distribution of power in the family, so that intrahousehold allocations are largely determined by remaining family members, such as mothers, instead. If these decision-makers care more about educational investments, child educational attainment may rise as a result.

Given this theoretical ambiguity, the effect of a father's migration on the educational outcomes of children in Mexico remains an empirical question. Estimation of this effect, however, is complicated by the likelihood that factors influencing parental migration also affect child educational attainment. For instance, if migrants are positively selected, it may be that more able fathers migrate and their more able children are more likely to stay in school and reach higher levels of schooling. Another source of concern that may bias the results is the case where some household-level shock induces the parent to migrate and also spurs the children to drop out or remain in school.

The main empirical attempts to deal with this endogeneity problem have relied on instrumental variables (IV) for identification. Hanson and Woodruff (2003) instrument for whether a household has an external migrant with the interaction between household-level characteristics and historical migration rates at the state level. They find that 10-15 yearold children in migrant households complete significantly more schooling than their peers in non-migrant households. Using a similar identification strategy, McKenzie and Rapoport (2011) find that migration lowers schooling for 16-18 year-old boys and argue that migration may impart a disincentive effect on children in the household.

As is often the case with instrumental variables methods, the exclusion restriction leaves 
these estimates open to criticism. For instance, historical migration rates might be indicators of the level of development in the community and therefore the prevalence and quality of schools in the area which affect children's educational attainments directly. Antman (2011b) proposes an alternative IV strategy based on labor market conditions in the U.S. cities which migrants are more likely to choose as destinations, but the analysis focuses on children's time spent working and studying, rather than ultimate educational attainment which is the focus here.

This paper proposes a straightforward solution to the endogeneity problem by relying on the variation in siblings' ages at the time of a parent's migration. Since older children in the same family are less likely to be enrolled in school and less likely to return if they drop out, their schooling outcomes are less likely to be affected by parental migration compared with those of their younger siblings. ${ }^{4}$ In the current study, the limiting case is a child that is at least 20 years-old, because a Mexican child beyond this threshold has in all likelihood completed her education, regardless of the migration patterns of her parents. ${ }^{5}$ By using a family fixed-effects regression model that permits us to hold constant effects which are common to all siblings, I can then control for all sources of observed and unobserved heterogeneity at the family level that might have resulted in a non-causal correlation between

\footnotetext{
${ }^{4}$ This observation is not so different from that employed by Bleakley and Chin $(2004,2010)$ who identify the effects of language skills on earnings and assimilation by arguing that older immigrant children are more likely to have difficulty acquiring a new language than their younger peers. Nobles (2007) also uses a similar strategy to estimate the effect of parental migration on child health, arguing that parental migration after a certain age should have no effect on child height.

${ }^{5}$ I later relax that assumption to consider a 15 year-old cutoff.
} 
the parent's migration and the child's educational outcome. ${ }^{6}$ Thus, the main virtue of this strategy is that it allows us to circumvent problems of positive or negative selection in a clean and straightforward way. Since the within-family strategy relies on differences in ages of children, I control for birth order and birth cohort effects in all specifications.

A standard critique of all fixed effects strategies is that they do not control for timevarying sources of endogeneity. However, since the fixed effects used here operate at the family level, for us to be concerned about such sources contaminating the estimates of the effect of migration on child education, there would have to be shocks that are correlated with outcomes for a subset of children within the family and also paternal migration. This could be the case for instance, if a time-varying shock affected paternal migration and children's educational outcomes based on their ages in precisely the same way as the proposed identification strategy. Another pitfall of this approach is that family level fixed effects will not control for unobserved heterogeneity at the level of the individual child. This might be a concern if, for instance, parents time migration to help more able children succeed in school. Since birth order and cohort effects are already included in the model, however, for the latter story to explain the results below, parents would have to perceive their younger children to be more able than their older children. To my knowledge, there is no evidence

\footnotetext{
${ }^{6}$ Barcellos et al. (2010) investigate gender discrimination across families in India and argue that sonbiased stopping rules will make comparisons between girls and boys difficult because unobserved family characteristics may be correlated with family size and gender composition. Family fixed effects will only correct for these sources of endogeneity if they are fixed over time. Evidence from Mexican fertility patterns presented in Dahl and Moretti (2004), however, suggest that parents are biased in favor of sons. Thus, if this type of endogeneity biases any of the estimates here, I would expect it to act as a bias against finding evidence of gender discrimination in favor of girls.
} 
to suggest that this is the case.

A virtue of the identification strategy used here is that it can be easily extended to allow the impact of parental migration to vary depending on the age of the child at the time of the parental absence. Distinguishing effects based on the child's age at the time of the parent's migration also brings this paper into relation with the literature on child development and family structure which investigates the effects of father absence on children at different age groups in the context of divorce and separation. In addition, this paper contributes to the migration literature by separating out the effects of paternal migration to the U.S. from the effects of paternal migration within Mexico, a distinction that most studies ignore. ${ }^{7}$ Since both domestic and international migration involve absence from the home, this distinction is important because it allows us to tease out the relative importance of father absence as a potential mechanism driving the overall effect of parental migration on children's human capital investments.

Overall, this paper establishes a positive effect of paternal U.S. migration on children's educational attainments, but the statistically significant results apply mainly to girls, suggesting that pushing a father's U.S. migration earlier in his daughter's life can lead to an increase in her educational attainment of up to 1 year relative to delaying migration until after she has turned $20 .^{8}$ At the same time, a father's domestic migration experience does

\footnotetext{
${ }^{7}$ Kroeger and Anderson (2011) also include both domestic and international migration measures to estimate the impact on schooling of children in Kyrgyzstan. Since they do not observe actual migration of household members, however, they focus on receipt of domestic versus international remittances

${ }^{8}$ This is in line with Acosta (2011) who finds that remittances result in increased schooling for girls, but not boys in El Salvador. In contrast, other studies have found negative effects of migration on schooling outcomes for girls, a result that is thought to be linked with an increase in housework for girls in particular
} 
not play a significant role in the educational outcomes of his children, suggesting that father absence is not a major factor influencing these estimates. Thus, policymakers should view international migration as a pathway by which families may raise the educational attainments of girls in particular. The remainder of the paper is structured as follows. Section 2 considers the implications of child age at parental migration within the context of the literature on parental absence. Section 3 discusses the data used in this analysis and highlights pertinent summary statistics. Section 4 reviews the empirical strategy and regression models to be estimated. Section 5 reports the results of the estimation and discusses possible interpretations. Section 6 concludes.

\section{Parental Absence and Child Development}

The question of whether parental presence matters to the educational outcomes of children has long been the subject of research by social scientists studying the effects of family structure on children in the U.S. ${ }^{9}$ In the economics literature, the research has largely been focused on the aftermath of divorce and family separation, and therefore primarily surrounds the consequences of the biological father's absence from the child's home, as well as the potential income shocks that may accompany this change.

For the most part, studies on the effects of family structure on children find a negative impact of father absence on educational attainment, and differ mainly in the magnitude of

\footnotetext{
(Meyerhoefer and Chen 2011, McKenzie and Rapoport 2011).

${ }^{9}$ Booth (1995) is one of a handful of papers that considers the effects of father absence on children outside of the U.S. While the study is relevant because it considers the effects of father's migration, it does not address the endogeneity of paternal migration.
} 
their estimates and their means of identification. Grogger and Ronan (1995) exploit variation within the family in the number of years children spend in the home and find that fatherlessness reduces educational attainment for whites and Hispanics. Similarly, Sandefur and Wells (1997) find that living outside a two-parent family and changes to family structure are all detrimental to children's education. Notably, studies by Ginther and Pollak (2004) and Lang and Zagorsky (2001) find that controlling for additional family background variables significantly weakens the estimated effect of family structure on children's educational outcomes. While there is comparatively little written on the case of parental absence in Mexico specifically, Giorguli Saucedo (2006) finds evidence that living with both parents delays labor force entry for Mexican children, suggesting these children have a greater opportunity to focus on schooling.

Some may question the extent to which other relatives may substitute for a migrant father's absence, and thus mitigate the impact of migration. According to Nobles (2006), half of children (ages 0-14) in Mexico with a migrant father live with an additional adult, however this measure considers anyone over the age of 14 to be an adult and a plurality of these additional adults is made up of older siblings. While Mexican households do appear to rely more heavily on extended family for support, existing research still finds the presence of biological parents in particular to make a significant difference for children's outcomes, at least in the U.S. (Ginther and Pollak, 2004).

Santrock's (1972) work is especially relevant because he considers the timing of a parent's absence in the course of a child's life and the gender-specific effects of father absence. In particular, he hypothesizes that children should be more negatively affected by father absence if their fathers depart earlier in life (before age six) as opposed to later in life since older 
children are able to compensate for the father's absence with peer attachments. Additionally, he argues that boys should generally be more negatively influenced by father absence than girls. Thomas' (1994) review of the child development literature also suggests that paternal absence has a greater influence on boys than girls. More generally, Bertrand and Pan (2011) find that boys and girls differ in their response to parental inputs and home environments in the U.S., with boys' non-cognitive development particularly responsive to these inputs. ${ }^{10}$

Of course, the permanence of family dissolution considered in the literature on father absence serves as one of the main distinctions between these studies and the case of parental migration considered here. In addition, the positive family income shock that may accompany a parent's U.S. migration will be felt simultaneously with the parental absence, potentially outweighing the negative effects of the latter. Nevertheless, the literature on father absence is an important jumping-off point for this study because it stresses the role of parental presence in the educational outcomes of children as well as the importance of considering the age of children during the parental absence.

\footnotetext{
${ }^{10}$ The wider literature on child outcomes also suggests that girls and boys respond differently to environments outside the home. Kling et al. (2007) review omnibus results from the Moving to Opportunity housing lottery experiment indicating that moving to a better neighborhood improves educational and health outcomes for girls, while having adverse consequences for boys. Similarly, Kling et al. (2005) show that the housing experiment was linked with lower crime rates for female youth, but more problem behavior for teenage boys, suggesting that boys and girls adapt differently to new environments.
} 


\section{Data Description}

\subsection{Data}

The data used for this project come from the Mexican Migration Project (MMP118), a collaborative research project between Princeton University and the University of Guadalajara covering the years $1982-83$ and $1987-2007 .{ }^{11}$ The MMP is a publicly available data set containing information on the migration patterns and a wide variety of characteristics of households in Mexico. While these households are randomly selected within community, communities are not randomly selected, so the MMP is not intended to be representative of Mexico as a whole. In its earliest period, the MMP focused mostly on rural communities in Western Mexico, a major point of origin for U.S. migrants. Since then, the MMP has expanded to include a broad range of communities from rural areas as well as small cities and major metropolitan areas and now covers communities in states throughout Mexico. The communities are typically sampled in the months of December and January when temporary migrants are more likely to be home with their families in Mexico. Massey and Zenteno (2000) provide evidence that the MMP reflects a reasonably accurate profile of Mexican migrants to the United States.

The MMP is of particular interest because of its rich migration and lifelong labor histories of the household head and his (her) spouse. ${ }^{12}$ For the purpose of investigating the importance

\footnotetext{
${ }^{11}$ The MMP is publicaly avaiable at http://mmp.opr.princeton.edu/. In principle all survey years are eligible to be included in the sample here provided respondents are interviewed in Mexico. This restriction eliminates the 1983 sample. All remaining survey years are included.

${ }^{12}$ According to the interviewer's manual (Durand et al, 2005), in the case of a couple, the head is the husband unless he is migrating and his wife does not know enough about her partner to answer questions
} 
of age of the child when the parent migrated, this is especially important because it can account for the timing of the migration trips taken by the head of household and his (her) spouse and therefore identify the ages of children when the migration was undertaken. As will be shown below, most migrants are male as are most heads of household; thus, most of the migration experience documented below will be that of the male head of household. The MMP is also quite useful in examining within-family effects because unlike other household data sets, information on all children of the household head is provided regardless of whether they currently coreside with the parents. While the information on U.S. migration for the head of household is extensive, the MMP only has limited information on the first and last migration trips of other members of the head's family, including the children of the head, so it is not possible to track the child's migration history.

One limitation of the survey is that it only identifies the relationship between the head of household and other members of the family and household. Since the focus of this paper is on children of migrants, I restrict the sample to children of the heads of household. ${ }^{13}$ By far, most of the heads of household are men (around 80 percent), so most of the children are observed in relation to the household of their father. ${ }^{14}$ For purposes of documenting about his migration experience. In the latter cases, the wife is labeled as the head.

${ }^{13}$ Unfortunately, I have no additional information on household composition at the time of migration, thus ruling out an examination into the effects of migration on other children that may have resided in the household at the time of the head's migration.

${ }^{14}$ Note that this does not mean that the child will necessarily be living in the head's household at the time of the survey since non-resident children are included in the sample. This also does not restrict the nature of the household in which the child was living at the time of migration, since the migration data are constructed from retrospective histories. Unfortunately, I have no additional information on the household circumstances in which the child was living at the time of migration. 
both parents' migration experiences, I make the assumption that the spouse of the head of the household, if present, is also the parent of the children. This will mostly affect whether mothers are correctly identified, and, as will be shown below, the extent of mother's migration is very limited in any case.

Another limitation of the survey is that it does not collect comprehensive information on the timing of domestic migration. However, if parents with no U.S. migration experience have migrated domestically, including them with the sample of parents who have never left their children may lead to biased results. Since the MMP118 only collects information on first and last domestic migration, I use the lifelong labor histories of the head and spouse to construct a domestic migration history based on whether the individual changed jobs into another state within Mexico. Separating out the effects of domestic migration from U.S. migration marks another important contribution of this paper over other studies of Mexican migration in which only international migration is examined and in which domestic migrants are often treated similarly to those with no absence from the home.

Finally, any discussion of the effects of parental migration must consider the possibilities of a child migrating along with the parent. To be sure, potentially the most pivotal way that parental migration can affect a child's education is if the child migrates as well, thus confounding the effect of parental migration with the child's own migration experience. As the MMP does not contain comprehensive migration histories for children, I address this problem by excluding children whose first migration trip was before the age of 20, the period of childhood considered in this paper. This amounts to approximately 20 percent of the original child sample. In order to isolate single birth-year cohort effects, I also exclude children born before 1925 which results in dropping an additional 36 observations. This 
leaves me with 34,670 adult children who are at least 20 years-old and whose households are interviewed in Mexico. Twenty years of age is taken as the threshold after which a parent's migration no longer has any effect on a child's education because, as the descriptive statistics will attest to below, by that age, it is expected that a Mexican child will have completed his education. In the robustness section below, I lower the threshold to 15 years of age.

\section{[INSERT TABLE 1 HERE]}

\subsection{Descriptive statistics}

The sample of children who are at least 20 years-old at the time of the survey with no domestic or international migration experience prior to age 20 amounts to 34,670 individual child observations from 9,003 families. Table 1 describes the overall sample, showing that the average age of children in the sample is about 32 years-old. While Mexican schooling may be officially compulsory through grade 9 (U.S. DOE, 2002), in practice, many children fall below that threshold, and some sources report that more than $50 \%$ of Mexican children fail to reach this mandate (OECD 2010). In the sample used here, average educational attainment is about 8 years (median of 6 years), with an average of 7.8 years of schooling for girls and 8.1 for boys. This accords fairly well with the national average educational attainment of 8.8 years in 2004 from other sources (OECD 2010). In addition, almost 90 percent of the sample used here report fewer than 14 years of completed schooling, further justifying the assumption that most children are in fact finished with their educations by 20 years of age. This is also consistent with 2008 reports indicating that only $20 \%$ of Mexicans have reached tertiary education (OECD 2010). 
Table 1 also gives some sense of the extent of parental migration experienced by the children in the sample. To quantify this, I divide each child's life into six periods when the parent may have migrated: before the child was born, when the child was 0-4 years-old, when the child was 5-9 years-old, when the child was 10-14 years-old, when the child was 15-19 years-old, and when the child was at least 20 years-old. The average number of periods when either the mother or father was absent is about 1.1. The relatively low periods of parental absence supports focusing on the effect of the parent's first migration trip.

On the issue of parental migration, about 27 percent of children have fathers that migrated to the U.S. at some point, while around 3 percent have mothers that have done the same. About 18 percent have fathers who have migrated domestically, and about 6 percent have mothers who have migrated within Mexico. Conditional on having a father with U.S. migration experience, on average, the first trip began about two years before the birth of the child, while the first domestic migration experience was around one year before the child's birth. In contrast, those children with mothers who migrated within Mexico were on average about 2 years-old at the time of the mother's first domestic migration while children with mothers who migrated to the U.S. were on average closer to 15 years-old. This pattern of statistics confirms that it is mainly fathers in the households that have migration experience, and justifies this paper's focus on paternal migration. While paternal migration to the U.S. is more prominent than within Mexico, there is also a substantial fraction of fathers that have migrated within Mexico. As mentioned above, this sample is restricted to children with no migration experience before the age of 20 . Of these children, it is interesting to note that their subsequent migration patterns also occur early in life. The average ages of a child's first U.S. and domestic migration trips are both around 26 years of age. 


\subsubsection{Migration and remittances}

One of the most important potential factors distinguishing the effects of international versus domestic migration on education is the difference in remittances. A priori, I would expect the remittances to be much larger coming from the U.S. as the wage is much higher in the U.S. than in Mexico. Unfortunately, the MMP does not collect information about domestic migration remittances and international remittances are only collected for the last U.S. migration. This effectively prohibits us from matching migration episodes during the periods of the child's life under consideration with any data on remittances from the migrant parents. Nevertheless, the MMP does collect some data on wages during the last domestic migration, last job in Mexico, and last job in the U.S., as well as remittances on the last U.S. trip that can suggest the potential differences in remittances that might stem from each activity.

\section{[INSERT FIGURE 1 HERE]}

To give some idea of the difference between earnings at home and during migration, Figure 1 plots median values for daily earnings associated with the last domestic migration, the last U.S. migration, and earnings at the last Mexican job for male heads of household over the period 1994-2003. ${ }^{15}$ Unfortunately, there is no information on hours spent working in Mexico, so I base my estimate of daily earnings on an 8-hour workday, 40 hour-work week, and 50 weeks worked per year for those respondents who quote earnings in anything other than a daily rate. As can be seen in the graph, median earnings during the last

\footnotetext{
${ }^{15}$ I selected this window of time because it is the ten year period following the change in currency to Mexican "new pesos" and thus avoids any confusion in record-keeping.
} 
domestic migration and earnings at the last Mexican job move very closely together, with both around $\$ 10$ to $\$ 20$ (2002 US dollars) per day. In contrast, earnings for migrants in the U.S. lie far above both of them, with earnings between $\$ 50$ and $\$ 60$ per day. In addition, the median level of U.S. remittances reported over this period is $\$ 295$, or about five to six times estimated daily earnings in the U.S. Thus, while there is considerable variation in both U.S. and Mexican wages, these data support the hypothesis that the financial benefits of U.S. migration are likely to be much greater than those from Mexican migration.

One might ask then, if there appears to be little benefit from domestic migration, why would people undertake it? One important caveat to note here is that all of the earnings data can be interpreted to be conditional on having a job, and the MMP does not collect specific information on unemployment. While I do not condition on values being greater than zero, there are very few zeros in the responses, suggesting that the latter are effectively conditional on having a job. Thus, it could be that people undertake domestic migration for greater employment opportunities, even if the actual wage paid is not much larger than the wage they could have earned had they been able to find a job at home.

Of course, these differences could be explained by migrant selection or other unobserved variables. There are also likely to be higher costs to international versus domestic migration, and the data do not allow for an analogous comparison of costs. Thus, this evidence is meant only to be suggestive of the possibility that there are much larger financial returns to U.S. migration than domestic migration, and that conditional on getting a job, domestic migration does not confer financial benefits much larger than staying home. The main commonality between U.S. and domestic parental migration would therefore appear to be parental absence from the home, a fact that will potentially enable us to difference out the 
effect of father absence on children's outcomes in the estimates of international parental migration on children's outcomes.

[INSERT TABLE 2 HERE]

\subsubsection{Variation in child age at the time of parental migration}

Table 2 shows the distribution of children with parental migration experience across the six groups based on child age at time of the father's migration. The bottom row sums over the previous entries in the respective column and thus displays the total number of children who experience paternal U.S. and paternal domestic migration at some point in their lives. Since I have excluded those children with no migration experience before age 20 , it is only possible that these children accompanied their parents after they were already adults, and thus when it was unlikely to have any further impact on their educational outcomes. Most notably, a majority of parents who migrate at some point do so before the birth of a child. Including these observations in the analysis is valuable because these children would not have experienced the absence of a parent during that migration trip, but could potentially benefit from remittances saved for future educational expenditures. They may also be affected by changes in information, for instance, if the migrant parent learned something about the returns to education or migration in particular that he then brought to bear on determining the educational investments in his children. In addition, Table 2 also shows significant variation in child age at the time of parental migration beyond birth, with about a third of the sample experiencing paternal migration between birth and 20 years of age. A much smaller fraction of fathers migrate for the first time after a child has turned 20, a fact that will potentially have an impact on the precision of some of the estimates below. 


\section{[INSERT TABLE 3 HERE]}

Since the variation in ages of siblings at the time of their parent's migration is critical for the analysis, it is important to establish the extent of this variation in the sample before turning to the fixed-effects estimation. Table 3 gives a sense of the number of families on which the main identification strategy rests, that is, the subset of families from Table 2 who had a child above and below the 20 year-old threshold at the time of migration. As documented in Table 3 Panel A, of the 238 families with at least one child 20 and older at the time of the parent's first migration, 136 also had at least one child who was below the cut-off. These families have close to 8 children on average, and the children below 20 will thus be members of the treatment group for whom parental migration affects educational attainment. Table 3 Panel B gives a more detailed sense of the variation which underlies identification of the effects of child age at departure by grouping observations from Table 2 into five year age categories based on children's ages at the time of the father's migration. Of the total 2,427 families in which fathers have some U.S. migration experience, 598 families have children in two, not necessarily adjoining age groups at the time of the father's first U.S. migration, while 240 families have children in 3 age groups at the time of the father's first U.S. trip.

\section{[INSERT TABLE 4 HERE]}

The fact that the main identification strategy rests on only 136 families naturally raises the question of whether this sample is representative of the larger population. Table 4 addresses the differences in the two samples by comparing summary statistics of families with a child above and below the 20 year-old cut-off at the time of the father's first U.S. trip 
with the remaining sample of families where children experienced paternal U.S. migration at some point in their lives. As can be seen in the table, the main differences are those we would expect to see in cases where one set of fathers has children that satisfy the criteria needed for identification. Namely, it appears that this set of fathers undertook migration later in life (47 versus 27 years old on average at the time of the first US trip), which explains why they have children above and below the 20 year-old cutoff at the time of their first migration. Thus, the fathers have less migration experience marked by fewer reported trips, and fewer months in the U.S. The fact that these fathers are older also explains why their children are older at the time of their first migration (12 versus 6 years before birth) and why they have more children on average at the time they are observed in the survey (7.8 versus 6.8 ). It is reassuring however, that the fraction of children that are girls does not appear to be statistically different across the two groups (both around 0.5).

Most importantly, there does not appear to be a statistically significant difference in the years of educational attainment of fathers in the two samples (around 3 for both groups) or the likelihood that households are headed by men (almost universal in both groups). For the smaller set of observations with non-missing data on earnings on the last U.S. migration as approximated using the assumptions on hours of work made above, the mean values are close in magnitude and not statistically significantly different, suggesting that neither group is more or less likely to be a successful migrant. The same is true for earnings at the last Mexican job. Thus, it seems the main differences between households are associated with the age of the father at the time of his first migration, which coincides with our ability to observe his children above and below the 20 year-old cutoff. Nevertheless, this does not rule out the possibility that age at the time of father's first migration is associated with other 
important differences not observed here, which might call into question the external validity of the results below.

\section{Empirical Strategy}

\subsection{Overall effect of parental migration on schooling}

As mentioned above, the empirical strategy I use to identify the effect of parental migration on education relies on the assumption that having a parent migrate for the first time when the child is twenty or older is akin to never having had a parent migrate at all. Thus, using family fixed-effects estimation allows me to compare such a child to his siblings who were at a more formative age when the parent undertook migration, and whose schooling patterns were consequently affected by the experience of parental migration. This amounts to estimating the following regression model:

$$
e d u_{i f}=d a d \_m i g \_U S_{i f} \beta_{1}+d a d \_m i g \_D O M_{i f} \beta_{2}+X_{i f} \gamma+u_{f}+v_{i f}
$$

where $e d u_{i f}$ is the number of years of schooling of child $i$ in family $f$, dad_mig_US $S_{i f}$ is a dummy variable equal to one if the father migrated to the U.S. before the child was 20 and zero otherwise and $d a d_{-} m i g_{-} D O M_{i f}$ is equal to one if the father migrated within Mexico before the child was 20 and zero otherwise. ${ }^{16}$ Thus, if a father had migration experience in

\footnotetext{
${ }^{16}$ One alternative would be to use explicit data on the duration of parental migration and thus examine the effect of an additional month of migration on children's educational attainments. Given that the migration episodes are all based on retrospective data, however, the explicit duration data are likely to be subject
} 
the U.S. and within Mexico before the child was 20, both dummy variables would be equal to one and if a father never migrated to the U.S. or within Mexico, both dummy variables would equal zero. $X_{i f}$ is a vector of control variables consisting of a dummy variable equal to one if the child is female (in the specifications that are not run separately by gender), a linear birth order variable, a dummy indicator for the oldest child, a dummy variable equal to one if the child is the youngest of the siblings, and a vector of dummy variables indicating into which single birth-year cohort the child was born. ${ }^{17}$ The birth cohort dummies address the concern that the difference in ages between siblings is picking up the overall increases in educational attainment Mexico experienced over the course of the last century. The family fixed effect, $u_{f}$, captures any observed or unobserved heterogeneity common to the siblings in family $f$, including characteristics of the parents and community of origin.

Ideally, this identification strategy would be able to not only establish whether the effects of parental migration on child education are positive or negative, but also illuminate the causal mechanisms at play. Controlling for Mexican domestic migration in the above specification is one attempt to inform that debate, since both migrant fathers in the U.S. and migrant fathers in Mexico will be absent from the home. ${ }^{18}$ Thus, the difference between to greater recall bias. In contrast, using the dummy variable approach also has the added value of not making as strict an assumption about the functional dependence of educational attainment on the duration of parental absence.

${ }^{17}$ As seen above, the number of children per family in the sample is relatively large, and thus, I opt for a linear birth order variable and variables indicating the oldest and youngest. This specification will also make for ease of comparison when the sample is split into girls and boys.

${ }^{18}$ It may also be that the father that migrates domestically may be able to return home more frequently, or in case of emergency, than the father who migrates internationally. Unfortunately, I have no data to investigate the extent to which this occurs in practice. 
the U.S. migration and domestic migration coefficients should capture effects that are specific to international migration, and consequently point to remittances as a potential causal mechanism.

\subsection{Education and child age during parental migration}

This paper also contributes to the literature on the impact of parental absence on child outcomes by discussing the effect of parental migration on child educational attainment based on the age of the child during the parent's absence. The regression model that informs this debate is the following:

$$
e d u_{i f}=\sum_{j=0}^{4} d a d \_m i g \_U S_{i f j} \beta_{1 j}+\sum_{j=0}^{4} d a d \_m i g \_D O M_{i f j} \beta_{2 j}+X_{i f} \theta+u_{f}+\varepsilon_{i f} \text {. }
$$

The variables describing the timing of the father's first migration trips are contained in dad_mig_US $S_{i f j}$ and $d a d \_m i g \_D O M_{i f j}$. For example, dad_mig_US $S_{i f j}$ is a dummy variable indicating whether the father made his first migration trip to the U.S. in one of the following $j$ periods: before the child was born, when the child was between 0 and 4 years of age, when the child was between 5 and 9 years-old, when the child was between 10 and 14, when the child was between 15 and 19, and with the base group including those children whose fathers migrated sometime after they had turned 20. The remaining variables are as stated in the previous section. ${ }^{19}$

\footnotetext{
${ }^{19}$ A previous version of this paper attempted to distinguish between the effect of the parent's first migration trip and parental migration episodes overall as well as the effects of maternal versus paternal migration. The results suggested that the main effects operated through the father's first migration trip and thus led to similar conclusions as those made here.
} 
I estimate equations (1) and (2) allowing for the family fixed effect to capture all observable and unobservable heterogeneity at the family level. This could include any family-level characteristics, such as genetic ability or work ethic, which affect both parental migration patterns and children's educational attainment. Since $u_{f}$ is likely to be correlated with the father's migration pattern, controlling for it in this manner represents a significant step forward in estimating the effects of parental migration patterns on education. The identifying assumption is that after including the family fixed effect, there is no correlation between the remaining individual error term and the factors predicting paternal migration.

As noted above, this strategy will not control for any endogenous shocks correlated with paternal migration that affect siblings differently within the family. This would be a concern, for instance, if some shock affected children's educational outcomes based on their ages in the same way we are attributing to paternal migration. For instance, a negative shock might induce the father to migrate and force a younger child still in school to drop out while not harming the educational attainment of his older sibling who has already completed school. This would generate a downward bias in the estimate of the impact of migration on educational attainment. However, if migration is costly and a positive shock can be thought to induce migration, the same line of reasoning would suggest we should expect an upward bias in the coefficient. Nevertheless, the main virtue of this strategy is that it allows us to account for family- or parental-specific characteristics that might be correlated with educational outcomes of children and parental migration patterns, as with cases of positive or negative migrant selection.

[INSERT TABLE 5 HERE] 


\section{Results}

\subsection{Overall effect of parental migration}

Before evaluating the results of the estimation of equation 1 with family fixed effects, a useful benchmark to explore for comparison is the standard OLS regression with no family fixed effects. Columns 1 through 3 of Table 5 report these results for the overall sample, as well as for the sample of boys and girls separately. In it we see that for the sample as a whole, as well as for the sample separated by gender, the OLS estimates show a statistically significant negative effect of paternal US migration on educational attainment of children ranging from -0.2 years for boys to -0.5 years for girls. Additionally, the OLS estimates of paternal domestic migration show a statistically significant positive effect of paternal domestic migration on children's educational attainment ranging from 0.66 years for boys to 0.44 years for girls. In all three columns, we can reject the hypothesis that paternal U.S. and domestic migration effects are equal as well as the hypothesis that the effects of migration are the same for girls as for boys. Since family fixed effects are not included in the preceding regressions, a possible explanation for these results is migrant selection patterns driven by heterogeneity across families. For instance, it may be that domestic migrants are positively selected and international migrants negatively selected, with children's educational performance positively correlated with the migrant selection patterns of their parents.

Including family fixed effects addresses this concern by comparing siblings within the same family. Columns 4 through 6 show the results from estimating equation 1 to determine the effect of parental migration on child education by comparing siblings based on whether their parents migrated before or after the child was 20 years-old. As shown in column 4 of Table 
5, a father's migration to the U.S. before the child reaches this critical age is associated with an increase in educational attainment of 0.26 years of schooling, but the point estimate is not statistically significant. Interestingly, a father's migration within Mexico is associated with very little difference in educational attainment relative to fathers with no migration experience. The relevant point estimate of -0.13 is not statistically significant.

As is common in the literature on parental absence and intrahousehold allocations, one might argue that boys' and girls' educational outcomes are determined differently even within families, and should thus be estimated separately. Columns 5 and 6 of Table 5 show the results of estimating equation 1 separately for boys and girls. Since family fixed-effects are included in the latter regressions as well, this specification is akin to comparing girls to their sisters and boys to their brothers in a model with a full set of gender interaction terms. While the effects of parental migration are not statistically significant for boys, the coefficient estimates on paternal U.S. and paternal domestic migration are fairly close in magnitude ( 0.23 for the former and 0.16 for the latter), and we can fail to reject that they are equal.

For girls, however, having a father migrate to the U.S. is associated with a statistically significant increase of 0.73 years of schooling while having a father migrate within Mexico is associated with no statistically significant difference in educational attainment (point estimate of -0.002). In contrast with the boys' results, we can reject the hypothesis that the effects of U.S. and domestic migration are the same for girls at the $10 \%$ significance level. ${ }^{20}$ Since domestic migration is not significantly affecting educational outcomes relative

\footnotetext{
${ }^{20}$ Interested readers may be curious about the results when the sample includes children who have migrated before the age of 20. The point estimates for paternal migration are not statistically significant for boys,
} 
to staying at home, it could be argued that paternal absence alone is not conferring a significantly detrimental effect on girls. These results also point to the possibility that girls are the main beneficiaries of paternal U.S. migration, however formal tests of the difference in point estimates between girls and boys do not allow us to reject the notion that the effects on boys and girls are in fact equal.

\section{[INSERT TABLE 6 HERE]}

\section{$5.2 \quad$ Effects by child age}

Table 6 shows the results from estimating the family fixed-effects regression in equation 2. As in Table 5, Table 6 shows that the effects of the individual control variables on educational attainment are as expected. There is a statistically significant negative effect of being female, a positive effect of being the oldest child, and a somewhat smaller, though positive effect of birth order on years of schooling, indicating that younger siblings in the family have higher levels of educational attainment. For the full sample of boys and girls estimated together, the point estimates on the variables indicating the period in the child's life when the father migrated to the U.S. are all positive, but not statistically significant. Similarly, the coefficient estimates on the variables indicating the period in the child's life when the father migrated domestically are not statistically significant, but carry a negative sign.

and for girls the magnitude of the point estimate on paternal U.S. migration drops to 0.4 , but remains statistically significant at the $10 \%$ level. Intuitively, this makes sense since one might expect the effect of a child's own migration experience to hamper educational attainment, and thus work against any positive effect of paternal migration. 
Looking at the results of the gender-specific estimation, we see the same pattern of boys not reflecting statistically significant gains from a father's U.S. migration in column 2 , with statistically significant effects only for the girls' results in column 3. As with the results from above, however, we generally cannot reject the hypothesis that the effects of paternal U.S. migration are equal for boys and girls, with the exception of having a father migrate when the child is 5-9 years old which carries a negative sign in the boys' regression. Nevertheless, column 3 shows that a father's first U.S. migration before the birth of a girl raises educational attainment by almost a full year (point estimate of 0.88) and is statistically significant at the $5 \%$ level. The remaining point estimates on a father's first U.S. migration are 1.0 for 0-4 year-old girls, 0.93 for 5-9 year-old girls, and subsequently drop to 0.71 for 10-14 year-old girls, and 0.65 for 15-19 year-old girls, although none of the differences in point estimates are statistically significant. The fact that the point estimates are very close in magnitude for the first three age groups again suggests that, at least for young girls, the absence of a father does not mitigate the positive effect of migration. The fact that none of the point estimates on paternal domestic migration are statistically significant in the girls' regression also supports this view. Nevertheless, we cannot reject the notion that the paternal U.S. and paternal domestic migration variables are equal, except for the indicator on having a father migrate domestically when a child is $15-19$ which carries a negative sign in the girls' regression.

[INSERT TABLE 7 HERE] 


\subsection{Robustness}

As mentioned in the Data section, one concern with the data used here is that full domestic migration histories are not available for the head and his spouse and are thus constructed from labor histories that document changes in jobs across state boundaries. Surely, there are some domestic migration episodes that are not captured by this categorization. In addition, this method may leave us with a base group of individuals who are less mobile by definition as they have never moved out of state after entering the labor force. To address the potential bias this approximation may cause, I return to the standard method in the literature of comparing children whose parents have had some U.S. migration experience with those children whose parents have had no U.S. migration experience but may have migrated domestically or not at all. While this reverts to the muddling of the base group which the above method was intended to resolve, one can also view a comparison of this exercise and the one above as a measure of the likely success of other studies that are unable to differentiate domestic migrants from those parents who have never separated from their children.

\section{[INSERT TABLE 8 HERE]}

The results of estimating the effect of parental U.S. migration with no distinction for domestic migrants can be found in Table 7. Compared with the results from Table 5, we see that the point estimates are very similar, again with the only statistically significant effect of paternal U.S. migration flowing to girls, who raise their schooling by about 0.73 years in response. Again, we cannot rule out the possibility that the true effects of paternal U.S. migration are equal for boys and girls. The analogue of Table 6 with the conflated base 
group of non-U.S. migrants can be found in Table 8. The effects of paternal U.S. migration on girls are again very similar to the results when controlling for domestic migration, and not statistically significant for boys. With the exception of the indicator for paternal migration while the child was 5-9 years old, however, we cannot reject the hypothesis that the effects of migration on boys and girls are in fact equal. Nevertheless, this exercise suggests that however faulty the construction of domestic migration variables may have been, controlling for domestic migration when using the fixed-effects estimator does not significantly alter the results. To the extent that paternal domestic migration was simply capturing the effect of father absence, this exercise thus adds to the perception that (at least temporary) father absence is not a significant determinant in child educational attainment.

\section{[INSERT TABLE 9 HERE]}

Table 9 investigates whether the results are sensitive to the arguably arbitrary cut-off of 20 years of age. As some might argue, in a country like Mexico, fifteen would be a more appropriate threshold for the assumed age beyond which parental migration should no longer affect child education. Certainly, the fact that some children beyond the 15 yearold threshold are still getting their educations, either because they had to repeat grades or they went above and beyond the average years of schooling, means that there may be some "contamination" of the control group in this exercise. Thus we would expect to see a fall in the magnitude of the effect of migration, as can be seen in Table 9, where the coefficient estimates drop somewhat and are no longer statistically significant. Nonetheless, we see that the point estimates of the effect of parental migration on education show the same pattern and are again highest for girls despite this change, although we cannot rule out the 
possibility that the effect is the same for girls and boys.

\subsection{Discussion}

Two points are suggested by the evidence above: (1) parental domestic migration does not seem to have a significant impact on the educational attainment of children and (2) parental U.S. migration appears to be linked more strongly with increased educational attainment patterns for girls than boys. On the first point, it is important to note that both parental migration to the U.S. and domestic migration to another state within Mexico involve some extent of father absence. Yet, there is no statistically significant difference between the educational outcomes of siblings who experienced parental domestic migration and those who did not. This suggests that father absence, at least for children of migrants, is not playing a major role in their educational outcomes. The similarity of the point estimates for the effects of paternal migration on girls before birth versus after birth is also supportive of this hypothesis. The fact that the point estimates for the effect of U.S. migration on child's educational attainment are similar whether or not we control for parental domestic migration also lends credence to this interpretation.

After addressing selection into migration with the family fixed effects strategy, what then is the main difference between migrating domestically and internationally? Potentially, children whose parents migrate to the U.S. might also learn about the returns to international migration, but if this effect were strong, we would expect to see it operating mainly on the educational investments of boys because men are more likely to migrate. Instead, boys show no statistically significant response to paternal migration. Summary evidence from 
Section 2 suggests that the main difference between international and domestic migration is the importance of remittances, as there is no significant wage premium to migrating out of state but there is a large premium to migrating to the U.S.

But why should these remittances appear to affect educational investments in girls more strongly than boys? Having already ruled out the likelihood that father absence is playing a significant role in the results, one possibility is that families are resource-constrained and when that constraint is relaxed by the father's migration abroad, these marginal dollars are more likely to be used to invest in educating girls. It may also be the case that migration strengthens the incentives for educating girls, for instance if paternal migration is associated with maternal employment and thus more information about the returns to education for women in particular. Alternatively, it may be that boys are also benefiting from parental migration, but in some unobserved way, for instance with increased food. ${ }^{21}$

Another point to consider is that since the mother is likely to remain at home with her children while the father is away, paternal U.S. migration likely marks both an increase in remittances and a shift in decision-making power toward the parent that remains in the household, namely the wife and mother. Antman (2010, 2011a) explores this possibility by examining household educational and clothing expenditures on girls versus boys directly and notes a rise in the fraction of resources toward girls coinciding with the migration of the head of household. Thus, the finding in this paper can be interpreted as further evidence that increasing bargaining power for women, coinciding with a simultaneous increase in resources, improves outcomes for girls and not boys, as has been found elsewhere in the

\footnotetext{
${ }^{21}$ Using data from Bangladesh, Pitt et al. (2010) suggest that this type of differential investment pattern across gender might make sense if the labor market returns to schooling and nutrition also vary by gender.
} 
literature on intrahousehold allocations (see for example, Duflo, 2003 and Thomas, 1994). However, having no information on preferences within the household, I cannot rule out that fathers determine the redirection of household resources toward girls from abroad or that both parents are in agreement over this decision. ${ }^{22}$

\section{Conclusion}

By using a family fixed-effects regression model to get around the endogeneity of parental migration and potential migrant selection, this paper has established a positive link between paternal U.S. migration and educational attainment for daughters of migrants. The evidence suggests that pushing a father's U.S. migration earlier in his daughter's life would lead to an increase in educational attainment of up to one year relative to delaying migration until after she has turned 20. Under the assumption that children whose parents migrate after the child has turned 20 are akin to having a parent who never migrated, the withinfamily approach yields estimates that having a father migrate before the child is 20 increases educational attainment by about 0.73 years for girls, with no statistically significant effect for boys. Nevertheless, we cannot rule out that the effects of paternal U.S. migration on girls and boys are in fact the same. At the same time, controlling for parental domestic migration does not have a statistically significant effect on educational attainment, nor does controlling for it affect the estimates of paternal U.S. migration, suggesting that father absence is not a major mechanism underlying the effects of paternal migration on educational

\footnotetext{
${ }^{22}$ See Ashraf, et al. (2009) for a discussion of the problem faced by international migrants in exerting control over the channeling of remittances.
} 
attainment. Consequently, policymakers should view international migration as a process leading to different outcomes than those from domestic migration. Indeed, the results here suggest that only the former may result in raising girls' educational attainments in particular.

To the extent these results are suggestive of a differential effect of paternal migration by gender, they are consistent with a story in which resource-constrained families use remittances to finance their daughters' educations. Since paternal migration also coincides with a shift in household structure, it may be that women are left as the primary decision makers in the household when a father migrates and these women invest their marginal dollars in the education of girls. This interpretation is consistent with the studies on intrahousehold allocations which find that increasing bargaining power for women is associated with better outcomes for girls and not boys (Duflo, 2003 and Thomas, 1994) and specific evidence showing that the migration of the head of household is associated with an increase in the fraction of expenditures devoted to girls (Antman 2010, 2011a). Further research should examine the relative importance of migrant fathers' preferences and their degree of control over the allocation of resources while they are away. Matching superior data sources with a more complete model of intrahousehold allocation during parental migration will also help distinguish between the competing hypotheses discussed here. 


\section{References}

Acosta P (2011) School attendance, child labour, and remittances from international migration in El Salvador. J Dev Stud 47(6): 913-36

Antman FM (2010) International Migration, Spousal Control, and Gender Discrimination in the Allocation of Household Resources. University of Colorado at Boulder Department of Economics Working Paper No. 10-15

Antman FM (2011a) International Migration and Gender Discrimination among Children Left Behind. Amer Econ Rev 101(3): 645-649

Antman FM (2011b) The Intergenerational Effects of Paternal Migration on Schooling and Work: What Can We Learn from Children's Time Allocations? J Dev Econ 96(2): 200-208

Antman FM (forthcoming) The Impact of Migration on Family Left Behind. In: Constant A, Zimmermann KF (ed) International Handbook on the Economics of Migration. Edward Elgar Publishing, Cheltenham, UK and Northampton, MA, USA

Ashraf N, Aycinena D, Martinez C, Yang D (2009) Remittances and the Problem of Control: A Field Experiment Among Migrants from El Salvador. Manuscript, University of Michigan

Barcellos SH, Carvalho L, and Lleras-Muney A (2010) Child Gender and Parental Investments in India: Are Boys and Girls Treated Differently? RAND Working Paper No. WR-756

Bertrand M, Pan J (2011) The Trouble with Boys: Social Influences and the Gender Gap in Disruptive Behavior. National Bureau of Economic Research Working Paper No.17541

Bleakley H, Chin A (2004) Language Skills and Earnings: Evidence from Childhood Immigrants. Rev Econ Stat 86(2): 481-496

Bleakley H, Chin A (2010) Age at Arrival, English Proficiency, and Social Assimilation Among US Immigrants. Amer Econ J: App Econ 2(1): 165-192 
Booth MZ (1995) Children of Migrant Fathers: The Effects of Father Absence on Swazi Children's Preparedness for School. Comp Edu Rev 39(2):195-210

Dahl GB, Moretti E (2004) The Demand for Sons: Evidence from Divorce, Fertility and Shotgun Marriage. National Bureau of Economic Research Working Paper No. 10281

Duflo E (2003) Grandmothers and Granddaughters: Old-Age Pensions and Intrahousehold Allocation in South Africa. World Bank Econ Rev 17(1): 1-25

Durand J, Lozano V, Romo R (2005) MMP/LAMP Interviewer's Manual. http://mmp.opr.princeton.edu/d Ginther DK, Pollak RA (2004) Family Structure and Children's Educational Outcomes: Blended Families, Stylized Facts, and Descriptive Regressions. Demography 41(4): 671-696

Giorguli Saucedo SE (2006) School Dropout Rates, Adolescent Labor and Family Structures in Mexico. In: Lezama JL, Morelos JB (ed) Population, City and Environment in Contemporary Mexico. El Colegio de México, México, DF, pp 223-257

Grogger J, Ronan N (1996) The Intergenerational Effects of Fatherlessness on Educational Attainment and Entry-Level Wages. National Longitudinal Surveys Discussion Paper, Bureau of Labor Statistics

Hanson GH, Woodruff C (2003) Emigration and Educational Attainment in Mexico. Manuscript, University of California San Diego

Lang K, Zagorsky JL (2001) Does Growing Up with a Parent Absent Really Hurt? J Human Resources 36(2): 253-273

Kling JR, Liebman JB, Katz LF (2007) Experimental Analysis of Neighborhood Effects. Econometrica 75(1): 83-119

Kling JR, Ludwig J, Katz LF (2005) Neighborhood Effects on Crime for Female and Male Youth: Evidence from a Randomized Housing Voucher Experiment. Quart J Econ 120(1): $87-130$ 
Kroeger A, Anderson K. (2011) Remittances and Children's Capabilities: New Evidence from Kyrgyzstan. DIW Working Paper No. 1170

Massey DS, Zenteno R (2000) A Validation of the Ethnosurvey: The Case of Mexico-U.S. Migration. Int Mig Rev 34(3): 766-793

McKenzie D, Rapoport H (2011) Can Migration Reduce Educational Attainment? Evidence from Mexico. J Popul Econ 24(4): 1331-1358

Meyerhoefer CD, Chen CJ (2011) The effect of parental labor migration on children's educational progress in rural China. Rev Econ Hous 9(3): 379-96

Nobles J (2006) The Contribution of Migration to Children's Family Contexts. California Center for Population Research Working Paper No. CCPR-046-06

Nobles J (2007) Parental Migration and Child Health in Mexico. Paper presented at the 2007 Population Association of America Annual Meeting, New York, NY, USA, 29-31 March 2007

Organization for Economic Cooperation and Economic Development (2010) CO3.1: Educational Attainment by Gender and Average Years Spent in Formal Education. http://www.oecd.org/dataoec

Pitt MM, Rosenzweig MR, Hassan N (2010) Human Capital Investment and the Gender Division of Labor in a Brawn-Based Economy. Yale University Economic Growth Center Discussion Paper No. 989

Reyes BI (1997) Dynamics of Immigration: Return to Western Mexico. Public Policy Institute of California, San Francisco, CA, USA

Sandefur GD, Wells T (1997) Using Siblings to Investigate the Effects of Family Structure on Educational Attainment. Institute for Research on Poverty Discussion Paper No. 1144-97

Santrock JW (1972) Relation of Type and Onset of Father Absence to Cognitive Development. Child Development 43(2): 455-469 
Thomas D (1994) Like Father, Like Son; Like Mother, Like Daughter: Parental Resources and Child Height. J Human Resources 29(4): 950-988

U.S. Department of Education (2002) Education Around the World: Mexico. http://www2.ed.gov/offices/C Yang D (2008) International Migration, Remittances and Household Investment: Evidence from Philippine Migrants' Exchange Rate Shocks. Econ J 118(528): 591-630 
Figure 1: Median Daily Earnings for Male Household Heads Over Time

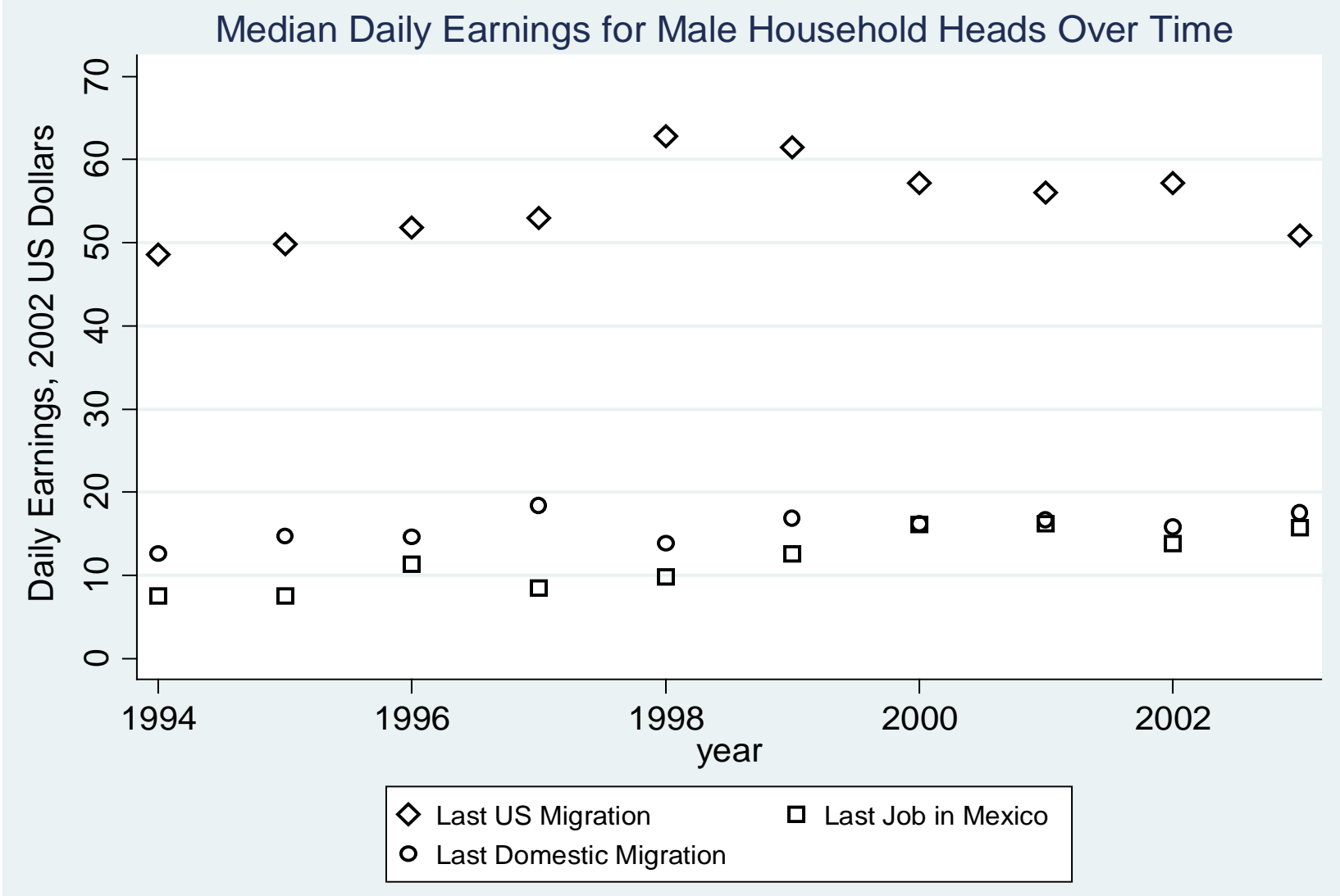


Table 1: Descriptive Statistics of Child Sample

Age

Female

Completed Education (Years)

Sibship Size

No. of Periods in Child's Life When Mom or Dad was Absent

\begin{tabular}{ccc} 
Mean & Std. Dev. & $\mathrm{N}$ \\
\hline 32.22 & 9.37 & 34670 \\
0.53 & 0.50 & 34670 \\
7.95 & 4.28 & 34670 \\
7.47 & 3.05 & 34670 \\
1.09 & 1.61 & 34670
\end{tabular}

Child's Parental Migration Experience

Father Migrated to US at Some Point

Father Migrated in MX at Some Point

Mother Migrated to US at Some Point

Mother Migrated in MX at Some Point

Age at Father's First US Departure ${ }^{a}$

Age at Father's First Domestic Departure ${ }^{\mathrm{a}}$

Age at Mother's First US Departure ${ }^{a}$

Age at Mother's First Domestic Departure ${ }^{a}$

Age at Child's First US Migration

$\begin{array}{lll}0.27 & 0.45 & 34670\end{array}$

$0.18 \quad 0.38 \quad 34670$

$\begin{array}{lll}0.03 & 0.18 & 34670\end{array}$

$0.06 \quad 0.23 \quad 34670$

$-2.35 \quad 12.86 \quad 9444$

$-1.27 \quad 13.12 \quad 6134$

$14.66 \quad 16.82 \quad 1180$

$1.76 \quad 13.80 \quad 1947$

$\begin{array}{lll}26.03 & 6.32 & 5890\end{array}$

$25.77 \quad 5.83 \quad 3336$

Age at Child's First Domestic Migration

${ }^{\mathrm{a}}$ This refers to the age of the child as constructed by the author. Note that this is allowed to be negative in order to reflect migration before the birth of the child. 
Table 2: How Many Children Experience Paternal Migration?

Distinguished by child's age during father's absence

How many children first experienced paternal migration during the specified period?

\begin{tabular}{lcccc}
\hline & \multicolumn{2}{c}{ Dad's 1st US trip } & \multicolumn{2}{c}{ Dad's 1st MX trip } \\
& Observations & Percent & Observations & Percent \\
\cline { 2 - 5 } Before Child's Birth & 5682 & $60.17 \%$ & 3629 & $59.16 \%$ \\
Child 0-4 Years-old & 1255 & $13.29 \%$ & 764 & $12.46 \%$ \\
Child 5-9 Years-old & 852 & $9.02 \%$ & 527 & $8.59 \%$ \\
Child 10-14 Years-old & 595 & $6.30 \%$ & 392 & $6.39 \%$ \\
Child 15-19 Years-old & 431 & $4.56 \%$ & 297 & $4.84 \%$ \\
Child At Least 20 Years-old & $\underline{629}$ & $\underline{6.66 \%}$ & $\underline{525}$ & $\underline{8.56 \%}$ \\
Total & 9444 & $100.00 \%$ & 6134 & $100.00 \%$ \\
\hline \hline
\end{tabular}




\section{Table 3: Variation in Child Age at Father's 1st US Departure}

Panel A: How many families have children above and below the 20 year-old cutoff?

Total number of families with at least one child 20+ when father first migrated to US

Those who also had at least one child under 20 at the time

136

Those who had no children under 20 at the time

102

Panel B: How much within-family variation is there in age at father's 1st US migration?

Number of age groups children fall into ${ }^{\mathrm{a}}$ Number of families

3240

$4 \quad 68$

$5 \quad 19$

$6 \quad 3$

Families with fathers who have some US migration

experience

${ }^{\mathrm{a}}$ Children within the family are grouped into the following age categories based on their ages at the time of the father's first U.S. migration: Before birth, 0-4, 5-9, 10-14, 15-19, 20+ 


\section{Table 4: Comparing groups of families with paternal migration experience}

Group 1: Families with children who have experienced paternal migration, but did not have children above and below the cut-off at time of father's first US migration

Group 2: Families with children above and below 20-year-old cut-off at time of father's first US migration

\begin{tabular}{lccc}
\hline & $(1)$ & $(2)$ & $(3)$ \\
\cline { 2 - 4 } Father's Total US Trips & Group 1 & Group 2 & Difference \\
& 4.451 & 2.178 & $2.273^{* * *}$ \\
Father's Total US experience (months) & $(0.125)$ & $(0.199)$ & $(0.518)$ \\
& 62.207 & 40.789 & $21.418^{* *}$ \\
Age of youngest child when father first departed for US & $(2.009)$ & $(5.025)$ & $(8.393)$ \\
& -6.220 & 12.066 & $-18.287^{* * *}$ \\
Age of father at time of his first US migration & $(0.265)$ & $(0.573)$ & $(1.096)$ \\
& 27.403 & 47.052 & $-19.649^{* * *}$ \\
Male head of household & $(0.197)$ & $(0.670)$ & $(0.825)$ \\
& 0.999 & 1.000 & -0.001 \\
Years of education, head of household & $(0.001)$ & $(0.000)$ & $(0.003)$ \\
Number of children in family & 3.154 & 2.867 & 0.287 \\
& $(0.065)$ & $(0.282)$ & $(0.277)$ \\
Fraction of daughters in family & 6.782 & 7.809 & $-1.027^{* * *}$ \\
Total number of families in each group & $(0.061)$ & $(0.247)$ & $(0.257)$ \\
\hline \hline
\end{tabular}

Note: All responses, except for youngest age of child, are results of direct questions in survey

Standard Errors below point estimates

*** significant at $1 \%$ level

**significant at $5 \%$ level 
Table 5: The Effect of Parental Migration on Child Education

Assuming children who experience paternal migration before age 20 make up the treatment group

\begin{tabular}{|c|c|c|c|c|c|c|}
\hline \multirow{6}{*}{$\begin{array}{l}\text { Father Migrated to US Before } \\
\text { Child Was } 20\end{array}$} & (1) & (2) & (3) & (4) & (5) & (6) \\
\hline & Boys \& Girls & Boys & Girls & Boys \& Girls & Boys & Girls \\
\hline & Years of & Years of & Years of & Years of & Years of & Years of \\
\hline & Education & Education & Education & Education & Education & Education \\
\hline & -0.37 & -0.201 & -0.51 & 0.26 & 0.229 & 0.729 \\
\hline & {$[0.048]^{* * *}$} & {$[0.075]^{* * *}$} & {$[0.063]^{* * *}$} & [0.207] & [0.378] & {$[0.291]^{* *}$} \\
\hline Father Migrated Within MX & 0.54 & 0.664 & 0.435 & -0.133 & 0.155 & -0.002 \\
\hline Before Child Was 20 & {$[0.060]^{* * *}$} & {$[0.091]^{* * *}$} & {$[0.080]^{* * *}$} & [0.248] & [0.509] & [0.353] \\
\hline \multirow[t]{2}{*}{ Birth Order } & -0.105 & -0.115 & -0.094 & 0.075 & 0.068 & 0.067 \\
\hline & {$[0.010]^{* * *}$} & {$[0.015]^{* * *}$} & {$[0.014] * * *$} & {$[0.019] * * *$} & {$[0.035]^{*}$} & {$[0.030]^{* *}$} \\
\hline \multirow[t]{2}{*}{ Oldest } & 0.454 & 0.465 & 0.446 & 0.428 & 0.47 & 0.322 \\
\hline & {$[0.064]^{* * *}$} & {$[0.095]^{* * *}$} & {$[0.087] * * *$} & {$[0.044] * * *$} & {$[0.083]^{* * *}$} & {$[0.068]^{* * *}$} \\
\hline \multirow[t]{2}{*}{ Youngest } & 0.889 & 0.957 & 0.811 & 0.005 & -0.135 & 0.065 \\
\hline & {$[0.074]^{* * *}$} & {$[0.110]^{* * *}$} & {$[0.100] * * *$} & {$[0.060]$} & [0.113] & [0.092] \\
\hline \multirow[t]{2}{*}{ Female } & -0.325 & & & -0.231 & & \\
\hline & {$[0.043]^{* * *}$} & & & {$[0.033]^{* * *}$} & & \\
\hline Family Fixed Effects (FEs) & NO & NO & NO & YES & YES & YES \\
\hline Birth Year Dummies & YES & YES & YES & YES & YES & YES \\
\hline Observations & 34670 & 16412 & 18258 & 34670 & 16412 & 18258 \\
\hline Number of families as FEs & & & & 9003 & 7170 & 7529 \\
\hline Number of families for ID & & & & 136 & 71 & 78 \\
\hline Avg. Value of Dep. Var. & 7.95 & 8.11 & 7.81 & 7.95 & 8.11 & 7.81 \\
\hline
\end{tabular}

Robust standard errors in brackets * significant at 10\%; ** significant at 5\%; *** significant at 1\%

${ }^{a}$ Number of families for ID refers to number of families with children above and below the cut-off age at time of father's migration 
Table 6: The Effect of Child Age During Parental Migration on Educational Attainment

\begin{tabular}{|c|c|c|c|}
\hline & $(1)$ & $(2)$ & (3) \\
\hline & Boys \& Girls & Boys & Girls \\
\hline & Education (Yrs) & Education (Yrs) & Education (Yrs) \\
\hline When was Dad's 1st US & & & \\
\hline Before Child Born & 0.473 & 0.678 & 0.877 \\
\hline & [0.300] & [0.551] & {$[0.433]^{* *}$} \\
\hline Child 0-4 Years-old & 0.277 & -0.008 & 1.012 \\
\hline & [0.287] & [0.524] & {$[0.407] * *$} \\
\hline Child 5-9 Years-old & 0.154 & -0.183 & 0.934 \\
\hline & [0.265] & [0.490] & {$[0.389]^{* *}$} \\
\hline Child 10-14 Years-old & 0.353 & 0.381 & 0.705 \\
\hline & [0.244] & [0.442] & {$[0.364]^{*}$} \\
\hline Child 15-19 Years-old & 0.265 & 0.288 & 0.649 \\
\hline & [0.214] & [0.400] & {$[0.284]^{* *}$} \\
\hline When was Dad's 1st dom & estic migration? & & \\
\hline Before Child Born & -0.406 & -0.013 & 0.122 \\
\hline & [0.359] & [0.674] & [0.535] \\
\hline Child 0-4 Years-old & -0.122 & 0.103 & 0.41 \\
\hline & [0.351] & [0.665] & [0.512] \\
\hline Child 5-9 Years-old & -0.035 & 0.264 & 0.426 \\
\hline & [0.326] & [0.629] & [0.480] \\
\hline Child 10-14 Years-old & -0.136 & 0.052 & 0.085 \\
\hline & [0.312] & [0.625] & [0.448] \\
\hline Child 15-19 Years-old & -0.165 & 0.154 & -0.131 \\
\hline & [0.259] & [0.530] & [0.369] \\
\hline Birth order & 0.075 & 0.067 & 0.068 \\
\hline & {$[0.019]^{* * *}$} & {$[0.035]^{*}$} & {$[0.030]^{* *}$} \\
\hline Oldest & 0.427 & 0.472 & 0.318 \\
\hline & {$[0.044] * * *$} & {$[0.083]^{* * *}$} & {$[0.068] * * *$} \\
\hline Youngest & 0.005 & -0.13 & 0.067 \\
\hline & [0.060] & [0.113] & [0.092] \\
\hline Female & -0.23 & & \\
\hline & {$[0.033] * * *$} & & \\
\hline Family Fixed Effects & YES & YES & YES \\
\hline Birth Year Dummies & YES & YES & YES \\
\hline Observations & 34670 & 16412 & 18258 \\
\hline Number of families & 9003 & 7170 & 7529 \\
\hline Avg. Value of Dep. Var. & 7.95 & 8.11 & 7.81 \\
\hline
\end{tabular}

Robust standard errors in brackets * significant at 10\%; ** significant at 5\%; *** significant at $1 \%$ 
Table 7: The Effect of Parental Migration on Child Education with Combined Base Group Base group includes children whose parents had domestic migration experience and those whose parents had no migration experience

\begin{tabular}{lrrr}
\hline & \multicolumn{1}{c}{$(1)$} & $(2)$ & \multicolumn{1}{c}{$(3)$} \\
\cline { 2 - 4 } & Boys \& Girls & \multicolumn{1}{c}{ Boys } & \multicolumn{1}{c}{ Girls } \\
Father Migrated to US Before Child Was 20 & 0.258 & 0.229 & 0.729 \\
& Education (Yrs) & Education (Yrs) & Education (Yrs) \\
Birth Order & {$[0.207]$} & {$[0.378]$} & {$[0.293]^{* *}$} \\
Oldest & 0.075 & 0.068 & 0.067 \\
& {$[0.019]^{* * *}$} & {$[0.035]^{*}$} & {$[0.030]^{* *}$} \\
Youngest & 0.428 & 0.47 & 0.322 \\
& {$[0.044]^{* * *}$} & {$[0.083]^{* * *}$} & {$[0.068]^{* * *}$} \\
Female & 0.005 & -0.135 & 0.065 \\
& {$[0.060]$} & {$[0.113]$} & {$[0.092]$} \\
Family Fixed Effects & -0.231 & & \\
Birth Year Dummies & {$[0.033]^{* * *}$} & & YES \\
Observations & YES & YES & YES \\
Number of families & YES & YES & 18258 \\
Number of families for ID & 34670 & 16412 & 7529 \\
Avg. Value of Dep. Var. & 9003 & 7170 & 78 \\
\hline \hline Robust stangard & 136 & 71 & 7.81 \\
\hline
\end{tabular}

Robust standard errors in brackets * significant at 10\%; ${ }^{* *}$ significant at 5\%; ${ }^{* * *}$ significant at $1 \%$ ${ }^{\mathrm{a}}$ Number of families for ID refers to number of families with children above and below the cut-off age at time of father's migration 


\section{Table 8: The Effect of Child Age During Parental Migration on Educational Attainment Revisited}

Base group includes children whose parents had domestic migration experience and those whose parents had no migration experience

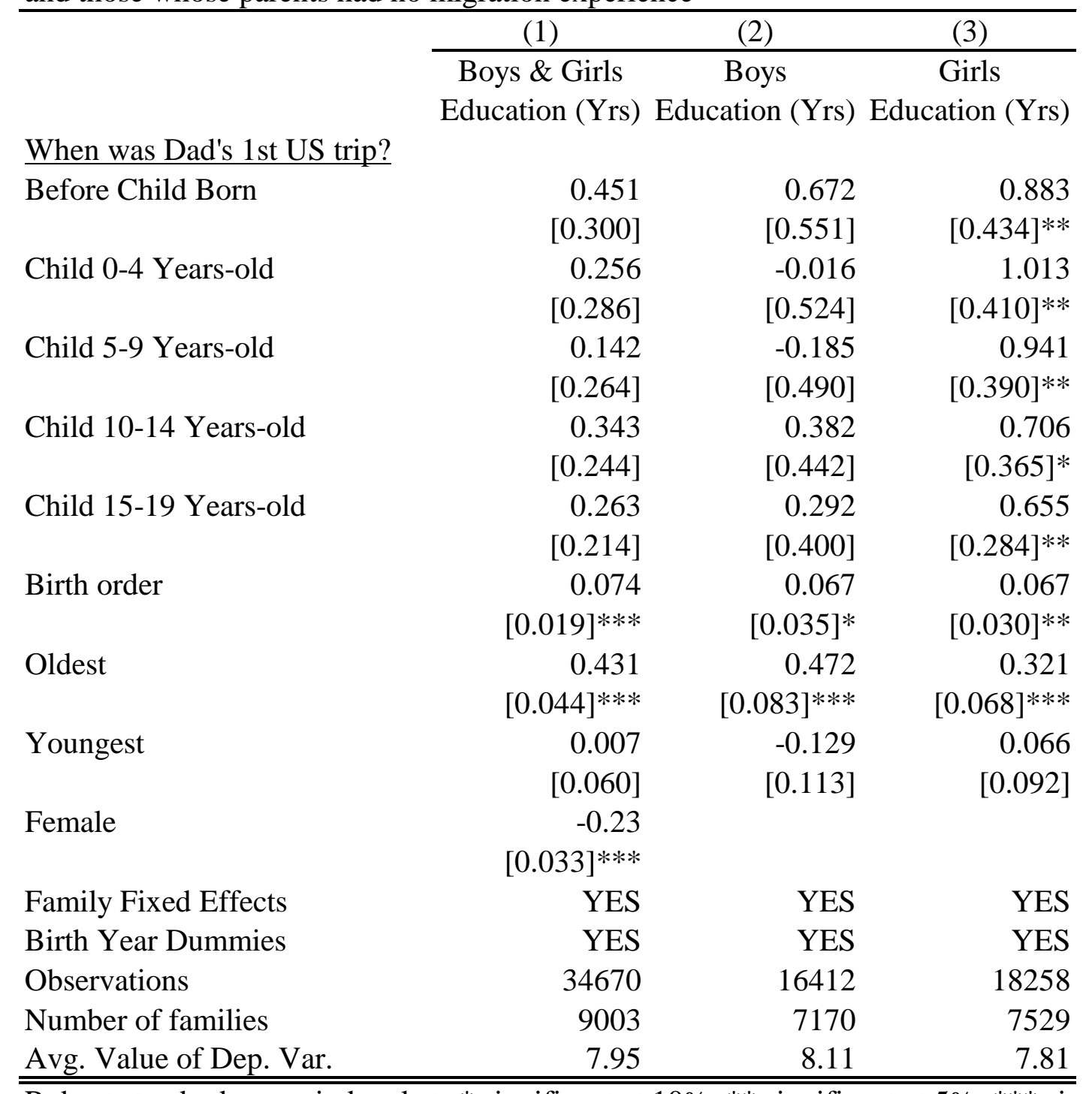

Robust standard errors in brackets * significant at 10\%; ** significant at 5\%; *** significant at $1 \%$ 
Table 9: The Effect of Parental Migration on Education; 15 Year-old Cutoff

Assuming children who experience paternal migration before age 15 make up the treatment group Base group includes children whose parents had domestic migration experience and those whose parents had no migration experience

\begin{tabular}{|c|c|c|c|}
\hline & (1) & (2) & (3) \\
\hline & Boys \& Girls & Boys & Girls \\
\hline & Education (Yrs) & Education (Yrs) & Education (Yrs) \\
\hline \multirow[t]{2}{*}{ Father Migrated to US Before Child Was 15} & 0.083 & -0.002 & 0.345 \\
\hline & {$[0.168]$} & [0.328] & [0.252] \\
\hline \multirow[t]{2}{*}{ Birth Order } & 0.075 & 0.068 & 0.067 \\
\hline & {$[0.019]^{* * *}$} & {$[0.035]^{*}$} & {$[0.030]^{* *}$} \\
\hline \multirow[t]{2}{*}{ Oldest } & 0.428 & 0.469 & 0.321 \\
\hline & {$[0.044] * * *$} & {$[0.083]^{* * *}$} & {$[0.068]^{* * *}$} \\
\hline \multirow[t]{2}{*}{ Youngest } & 0.005 & -0.136 & 0.066 \\
\hline & {$[0.060]$} & [0.113] & [0.092] \\
\hline \multirow[t]{2}{*}{ Female } & -0.231 & & \\
\hline & {$[0.033]^{* * *}$} & & \\
\hline Family Fixed Effects & YES & YES & YES \\
\hline Birth Year Dummies & YES & YES & YES \\
\hline Observations & 34670 & 16412 & 18258 \\
\hline Number of families & 9003 & 7170 & 7529 \\
\hline Number of families for ID ${ }^{a}$ & 183 & 83 & 111 \\
\hline Avg. Value of Dep. Var. & 7.95 & 8.11 & 7.81 \\
\hline
\end{tabular}

Robust standard errors in brackets * significant at 10\%; ** significant at 5\%; ${ }^{* * *}$ significant at $1 \%$

${ }^{a}$ Number of families for ID refers to number of families with children above and below the cutoff age at time of father's migration 